\title{
INVESTIGATIONS OF TIME AND ECONOMIC DIMENSIONS OF THE COMPLEX PRODUCT PRODUCTION CYCLE
}

\author{
Jelena Jovanović * \\ Technical College of Applied Studies, Čačak, Serbia \\ Dr Dragan Milanović \\ University of Belgrade, Faculty of Mechanical Engineering, Belgrade, Serbia \\ Dr Milić Radović \\ University of Belgrade, Faculty of Organizational Sciences, Belgrade, Serbia \\ Radisav Đukić \\ Office of the Manufacturing and Engineering Management, "Sloboda” Co. Čačak, Serbia
}

The features of contemporary production process of top organization and management methods are grounded on the principles of economies of times and the principles of lean production, a new philosophy of production. Production should be organized according to the push-pull principle, with minimum inventories, manufacturing only what is really necessary, neither too early, nor too late. The paper presents the design procedure and results of investigations on the production cycle of a complex product included in the production program of "Sloboda" - Čačak Co.

Key words: Complex product, Production cycle, Designing, Coefficient of running time, Current assets

\section{INTRODUCTION}

The achievement of Business and Production System (BPS) is largely dependent of adjusting production to the conditions of demand and application of innovative solutions in the sphere of technology, organization and management. To make the price competitive, the costs of business operations should be reduced, the observed losses should be eliminated or reduced to acceptable levels and resources should be engaged accordingly by using the corresponding management methods. Current assets should be engaged to the maximum in the production process, which is determined by the size of the production series, length of production cycle (PC) time, moment and manner of their engagement. The time and economic dimensions of PC should be mastered, so that the system responds promptly, in real time, no matter whether the orders are small-scale, large-scale, standard or special. Investigations of PCs implies a set of activities that have to define optimum production series, calculations for the amount of components required, cycle design, production preparation and launching, management of production activities, with current assets engagement and the analysis and calculations of the coefficient of material running time.

\section{OPTIMUM PRODUCTION SERIES}

To manufacture only what can be sold, to consolidate all requirements in a single spot, to enable flexible and economic production in smaller-scale series; all this represents the first and foremost principle of contemporary production. So, a problem is posed of inventing the relations that will enable the calculations of optimal production series, with minimizing total business operating costs. This problem comes to the fore particularly in series production performed in 'Sloboda' Co. Having in mind that the behavior of costs in series production depends on the volume of production (linear, non-linear, independent), the size of production series should be calculated in such a way that the opposite orientation of the nature of costs is optimally harmonized. This means that the optimum series size $\left(q_{0}\right)$ is characterized by minimal costs per unit of product. Respecting mentioned constraints, the analytical expression for calculations is defined by the relation (1):

$$
q_{o}=\sqrt{\frac{2 C_{n} Q}{c_{1} T}} \quad N=\frac{Q}{q_{o}}
$$


where:

$C_{n}$ are total fixed costs required to accomplish the order (Q), $C_{1}$ are variable costs per unit of product in unit of time (day), $T$ is period of time required to accomplish the delivery, $\mathrm{N}$ is the number of optimum-launched series. On the grounds of data from the Company's annual balance sheet, for the year 2011., corresponding technical documentation and relation (1), the optimum size of the production series was calculated, amounting to 3600 pieces.

\section{CALCULATIONS OF THE QUANTITY OF COMPONENTS}

The plan of components is the most significant production operational plan. Its creation requires: calculations of optimum production series, drawing of products' hierarchical structure graph (Figure 1), establishment of inventories in unfinished production (warehouses, work tasks), definition of planned technological waste and inventories at the end of the year for the continuity in the production.

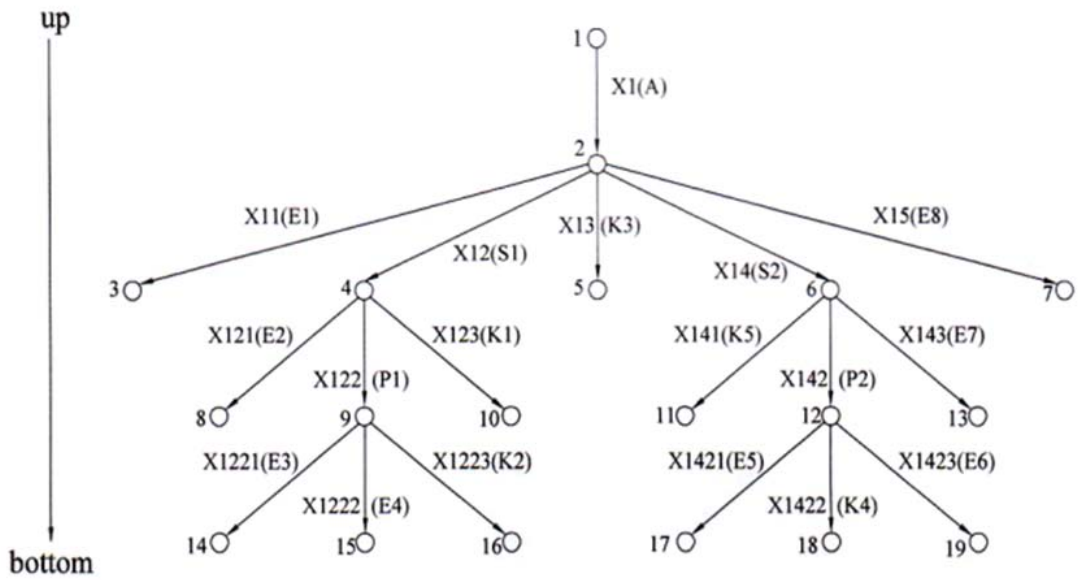

Figure 1: Graph of products' hierarchical structure

Planned quantities of components $\left(\mathrm{q}_{\mathrm{ijk}}\right)$ can be calculated using the following formulas:

$$
\begin{gathered}
x_{i j k}: q_{i j k}^{(1)}=m_{i j k} \cdot Q_{i}=n_{i j k} \cdot q_{i j} \\
x_{i j k}: q_{i j k}^{(2)}=\frac{n_{i j k} \cdot q_{i j}}{1-\check{S}_{i j k}}=\frac{m_{i j k} \cdot Q_{i}}{\Pi\left(1-\check{S}_{i j k}\right)} \\
x_{i j k}: q_{i j k}^{(3)}=\frac{n_{i j k} \cdot q_{i j}-q_{i j k}^{M}}{1-\check{S}_{i j k}}-q_{i j k}^{R N} \\
x_{i j k}: q_{i j k}^{(4)}=\frac{n_{i j k} \cdot q_{i j}-q_{i j k}^{M}}{1-\check{S}_{i j k}}-k \cdot q_{i j k}^{R N}
\end{gathered}
$$

where: $x_{i j k}$ is the component designation, qijk are planned quantities of components, $\breve{S}_{i j k}$ is the planned waste, $\mathrm{q}_{\mathrm{ijk}}{ }^{\mathrm{M}}$ are quantities of components in a warehouse, $q_{i j k}{ }^{R N}$ are quantities of components in launched work tasks, $\mathrm{k}$ is the coefficient that takes into account work task accomplishment level (per cent), mi is the quantity of the i-th component in a final article, $n_{i}$ is the quantity of the i-th component in the first superior level of a hierarchical scheme. For the optimum quantity of 3600 pieces of a complex product, using the corresponding formulas $(2)-(5)$, calculations were made for the quantity of components required for further analysis (Table 2).

\section{PRODUCTION CYCLE DESIGN}

The technological (ideal) PC comprises the time required to perform all operations $\left(\mathrm{t}_{\mathrm{i}}\right.$ ) according to the technological procedure on all products of the optimum series $\left(q_{0}\right)$. The workpiece movement plays important role in calculating the technological cycle, where movement procedures can be consecutive (6), parallel (7) and combined (8, $9)$. Combined movements are most commonly encountered in a series production.

$$
\begin{gathered}
T_{t u}=q_{o} \cdot \sum_{i=1}^{m} t_{i} \\
T_{t p}=\sum_{i=1}^{m} t_{i}+t_{i \max }\left(q_{o}-1\right) \\
T_{t k}=\sum_{i=1}^{m} t_{i}+\left(q_{o}-1\right)\left(\sum_{k} t_{k}-\sum_{j} t_{j}\right) \\
k: t_{k-1}<t_{k} \geq t_{k+1} \quad j: t_{j-1} \geq t_{j}<t_{j+1}
\end{gathered}
$$

The complexity of a product imposes multi-level approach to the analysis and design of PCs, be- 
cause production interferes with the assembly of units, sub-units and final article, so that parallel PC proceeding is possible by the stages of manufacturing and assembly. Using above presented considerations, calculations of the PC length for each operation will be made according to formula (10), in compliance with the adopted work organization, while PC for components will be calculated based on a combined workpiece movement applying the relations (11) and (12).

$$
\begin{gathered}
\tau(p f)_{i}=\frac{q_{p f}}{q_{S_{i}} \cdot S_{n_{i}} \cdot r_{m_{i}} \cdot p_{n_{i}}} \\
T_{p f}=\tau_{(p f)_{1}}+\left(n_{o p f}-1\right) \cdot \tau+\sum_{p}\left(\tau_{p}-\tau_{p-1}\right) \\
p: \tau_{p}>\tau_{p-1}
\end{gathered}
$$

The designed PC length of a complex product can be determined using a network diagram, a gantogram (Figures 3 and 4) or calculations to define the longest path in a complex-productstructure graph (Figure 1) in compliance with relation (13):

$$
T_{c p}=\max \left\{T_{(i-j)},(i-j)=1, l\right\}
$$

where: $T(p f)_{i}$ is PC length of the i-th operation of the observed production stage by days, $p f$ is the designation of the production stage (component), qpf is planned quantity $p_{f}, q_{S i}$ is the capacity in a shift of the i-th operation, $S_{n i}$ is the number of work shifts during the day on the i-th operation, rmi is the number of workplaces where production of the i-th operation is organized, pni is norm accomplishment on the i-th operation, Tpf is the designed PC length pf, $T(p f)$, is the designed $P C$ length of the first operation of the observed pf, nopf is the number of operations pf (from the technological procedure), $p$ is the designation of the operation that satisfies the condition: $T p>T_{p-1}$, Tcp is the designed PC length, $T(i-j)$ is the PC length of production stages found on the (i-j)-th path of a complex-product structure ( $i$ is the designation of the graph initial node, $j$ is the designation of the graph terminal node), I is the total number of paths in a graph that connect the initial with the terminal nodes, $\mathrm{T}$ is average backup time between operations (compensation for all losses in PC).

\section{PRODUCTION CYCLE ANALYSIS AND CALCULATIONS OF THE COEFFICIENT OF RUNNING TIME}

Unlike the technological (Tci) and designed PC (Tcopt) length, the actual (Tcs) length, apart from production (technological) time, includes PC non-production time and disruptions that cause losses Gc (Figure 2). In most cases PC disruptions are the result of inconsistency of production processes, bottlenecks in production, shortage of material, tools and energy, poor organization and handling of workplaces, stoppages due to machine breakdown, tool failure and lack of discipline in workers.

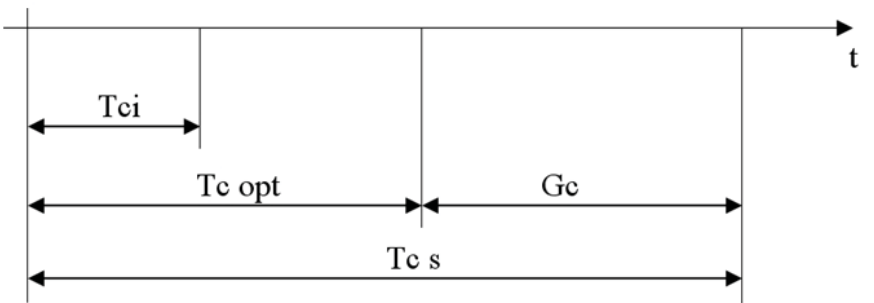

Figure 2: Production cycle duration

On the grounds of designed operation cycles (Tcp) and components involved in a complex product, production documentation was launched. The designed but also subsequently accomplished dates of the initiation and termination of production are recorded in a production date chart, a constituent part of work tasks. These data were used to determine the actual PC lengths (Tcs) (Tab. 1) and the coefficients of material running time $(\mathrm{Kp})$ were calculated applying the relation (14).

$$
K_{p}=\frac{T_{c S}}{T_{c p}}, \quad K_{p}=1+\frac{G_{c}}{T_{c p}}
$$

The coefficient of running time indicates how much the actual PC length is longer than the designed one. Table 1 shows the designed and actual PC lengths of all production stages of the analyzed complex product, losses in the cycle and corresponding values of the running time coefficient. On the grounds of the PC designed, Tcp $=96$ days, and actual, Tcs $=122$ days, length, the running time coefficient of a complex product $\mathrm{Kp}=1.27$ was established. 
Table 1: PC lengths (Tcp and Tcs), losses in the cycle and coefficient of material running time

\begin{tabular}{|c|c|c|c|c|c|}
\hline \multirow{2}{*}{\multicolumn{2}{|c|}{$\frac{\mathrm{T}_{\mathrm{cp}}, \mathrm{K}_{\mathrm{p}}, \mathrm{T}_{\mathrm{cs}}}{\text { Production stage }}$}} & \multirow{3}{*}{$\frac{\begin{array}{c}\text { Designd PC } \\
\text { lenght } T_{c p} \text { (days) }\end{array}}{3}$} & \multirow{3}{*}{$\frac{\begin{array}{c}\text { Actual } P C \text { lenghts } \\
\mathrm{T}_{\text {cs }} \text { (days) }\end{array}}{4}$} & \multirow{3}{*}{$\begin{array}{c}\begin{array}{c}\text { Losses in the } \\
\text { cycle }(\%)\end{array} \\
5=(4-3) / 4\end{array}$} & \multirow{3}{*}{$\begin{array}{c}\begin{array}{c}\text { Coeficient } \\
\text { of running time } K_{p}\end{array} \\
6=4 / 3\end{array}$} \\
\hline & & & & & \\
\hline 1 & 2 & & & & \\
\hline \multirow{8}{*}{ Elements } & $E_{1}$ & 7 & 9 & 22 & 1.29 \\
\hline & $\mathrm{E}_{2}$ & 14 & 19 & 26 & 1.36 \\
\hline & $E_{3}$ & 14 & 18 & 22 & 1.29 \\
\hline & $E_{4}$ & 12 & 17 & 29 & 1.42 \\
\hline & $E_{5}$ & 14 & 20 & 30 & 1.43 \\
\hline & $\mathrm{E}_{6}$ & 40 & 51 & 22 & 1.28 \\
\hline & $E_{7}$ & 13 & 17 & 24 & 1.31 \\
\hline & $\mathrm{E}_{8}$ & 14 & 19 & 26 & 1.36 \\
\hline \multirow{2}{*}{ sub-assemblies } & $\mathrm{P}_{1}$ & 17 & 20 & 15 & 1.18 \\
\hline & $\mathrm{P}_{2}$ & 16 & 20 & 20 & 1.25 \\
\hline \multirow{2}{*}{ assemblies } & $\mathrm{SK}_{1}$ & 12 & 14 & 14 & 1.17 \\
\hline & $\mathrm{SK}_{2}$ & 24 & 30 & 20 & 1.25 \\
\hline final assembly & $A$ & 19 & 21 & 10 & 1.11 \\
\hline
\end{tabular}

Note: Tcs value was established on the grounds of production monitoring and analysis of production and plan documentation

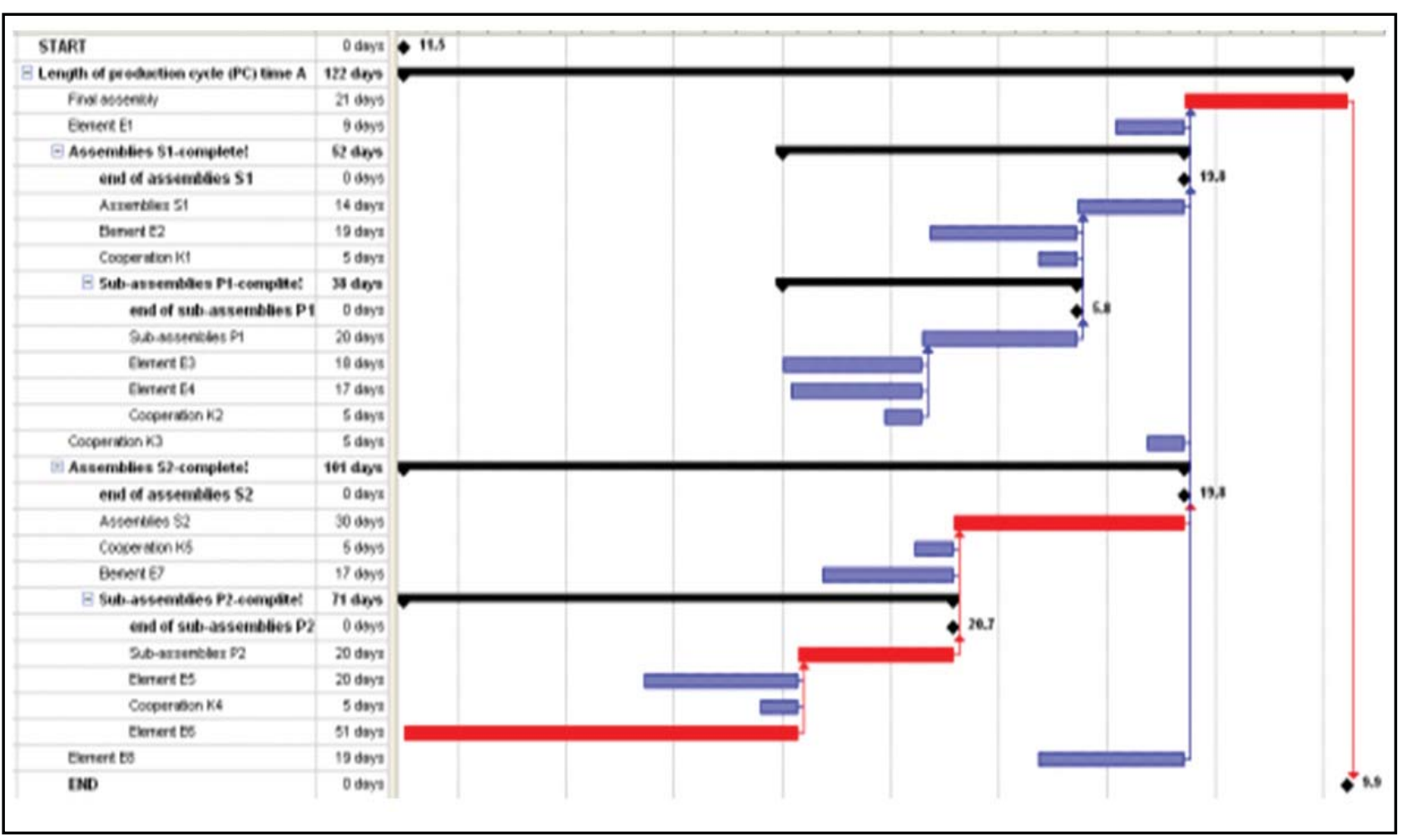

Figure 3: Gantt diagram - The latest beginning 


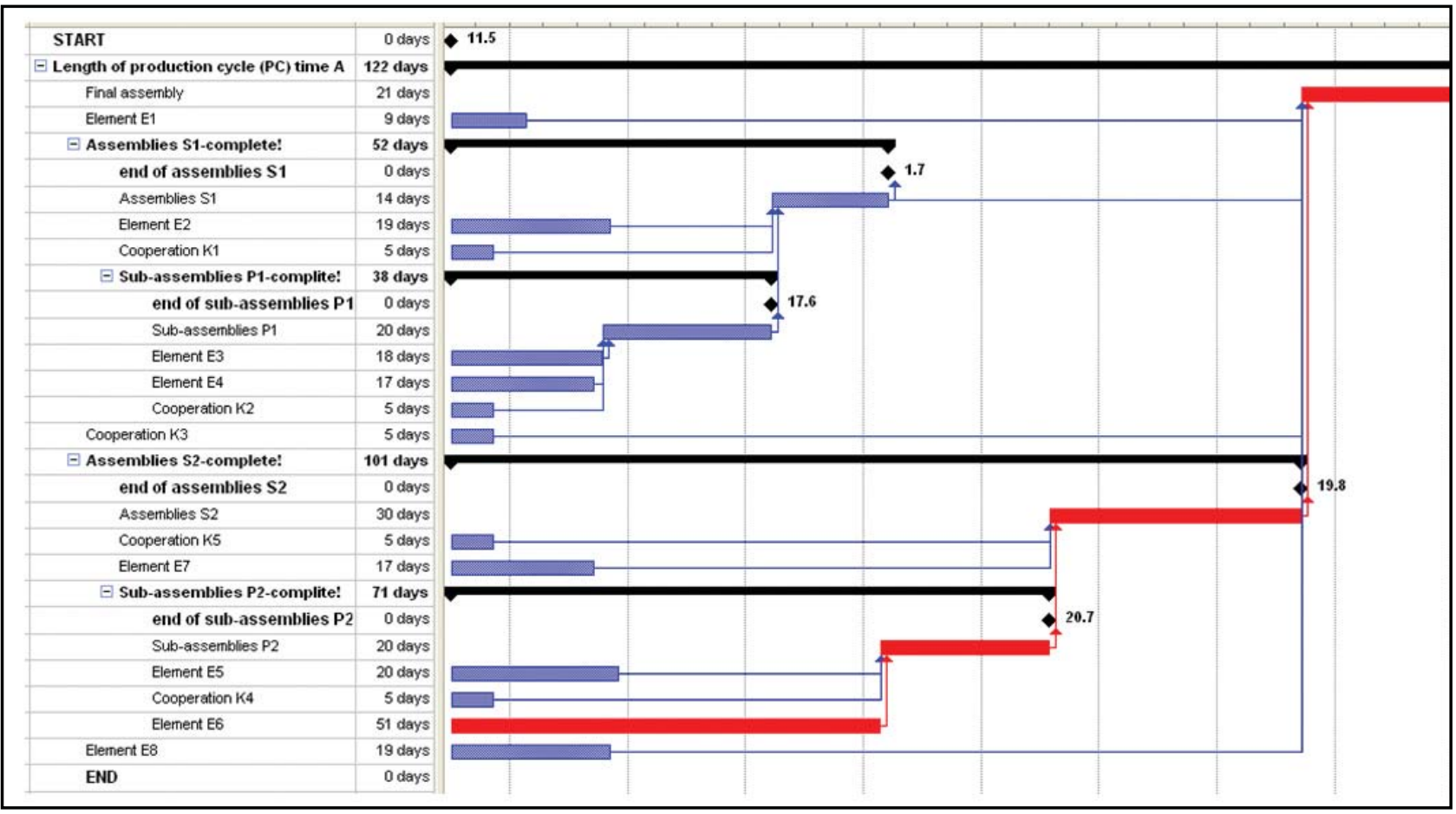

Figure 4: Gantt diagram - the earliest beginning

\section{CURRENT ASSETS ENGAGEMENT}

The basic purpose of current assets is to finance the production process, i.e., to settle current obligations, to supply the material and to pay salaries. Unlike fixed assets partially spent in the production process, current assets are a part of business assets that are entirely spent in the production process and their overall value is transferred onto the product. Current assets can be engaged in the production process in a smaller- or larger-scale, depending on the production series size, time period, moment and manner of engagement. Business operating costs (Tp) can be calculated using the formula (15):

$$
\begin{gathered}
T_{p}=T_{m}+T_{r}+T_{o}=T_{m}+T_{r}+O \cdot T_{p} \Rightarrow \\
T_{p}=\frac{T_{m}+T_{r}}{1-O}
\end{gathered}
$$

Other costs (To) are divided into variable and constant, relation (16):

$$
T_{o}=O \cdot T_{p}=T_{o v}+T_{o c}=0,2 \cdot T_{o}+0,8 \cdot T_{o}
$$

Using previous formula, one can derive the formula for calculating the value of norm-hours for other variable costs (VNČ)ov:

$$
\begin{aligned}
& T_{o v}=\sum W_{o v_{i}} \cdot q_{i}^{(4)}=\sum t_{i} \cdot q_{i}^{(4)} \cdot(V N \check{C})_{o v} \Rightarrow \\
& W_{o v}=t_{i} \cdot(V N \check{C})_{o v} \Rightarrow(V N \check{C})_{o v}=\frac{T_{o v}}{\sum t_{i} \cdot q_{i}{ }^{(4)}}(17)
\end{aligned}
$$

Current assets engaged prior to the beginning of production (point P, Fig. 5) amount to 17093264 dinars, relation (18):

$$
\begin{aligned}
P=T_{O C} & +\sum_{i}\left(q_{i}^{(2)}-q_{i}{ }^{(4)}\right) \cdot\left(W_{r_{i}}+W_{o v_{i}}\right)+ \\
& +\sum_{i}\left(q_{i}^{(2)}-q_{i}^{(3)}\right) \cdot W_{m_{i}}
\end{aligned}
$$

Current assets engagement depending on the actual PC length will be calculated using the gantograms (Figures 3 and 4) and relation (19).

$O_{s i}=T_{m_{i}}+a_{i} \cdot X_{i}, a_{i}=\frac{T_{r_{i}}+T_{o v_{i}}}{T_{c s_{i}}}, X_{i}=1,2, \ldots, T_{c s_{i}}$

Results are presented in Tab. 3, correlation coefficient and regression curves are defined by relations (20) and (21), and diagrams of current assets engagement are given in Figures 5 and 6. 


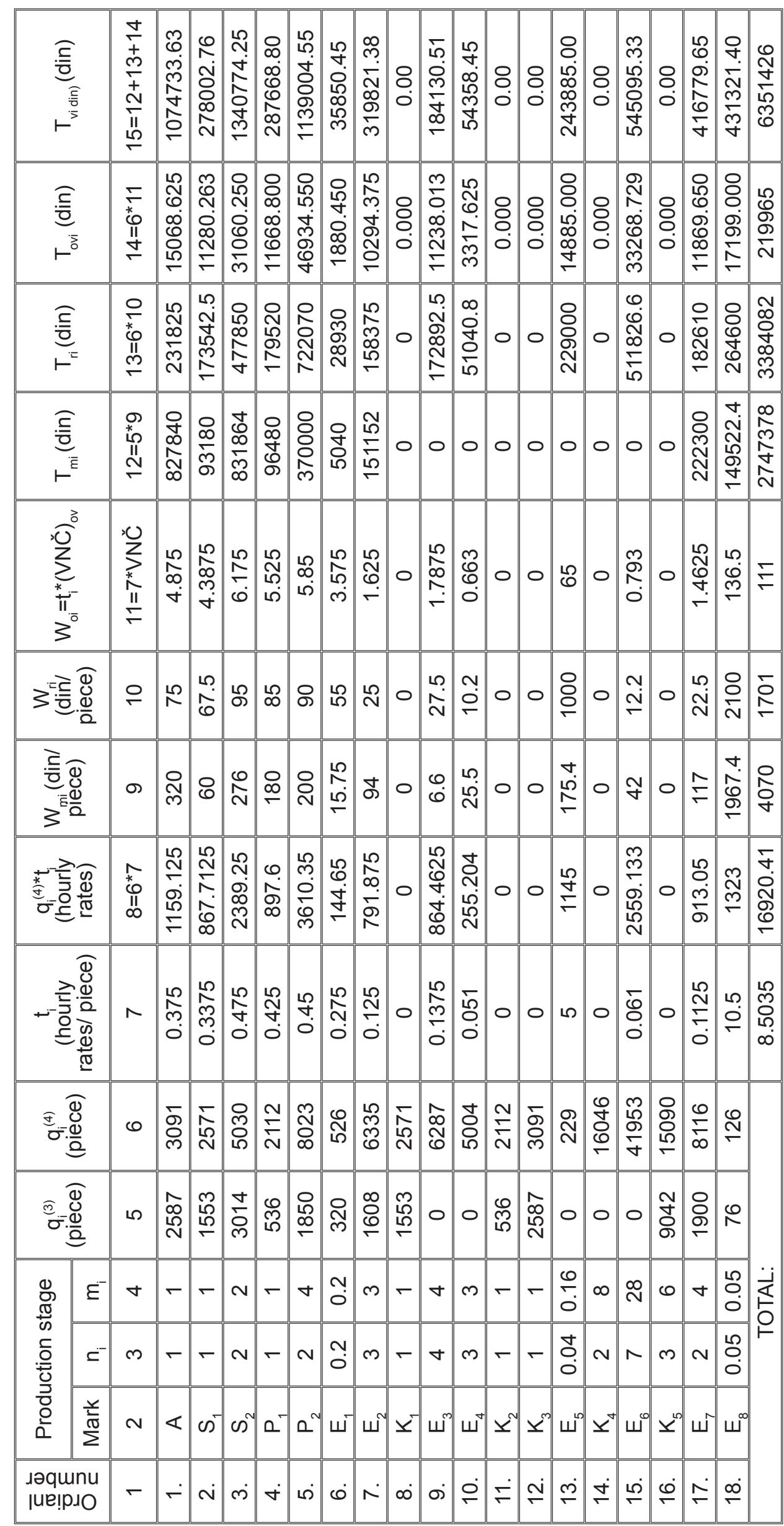


Table 3: Dynamics and amount of current assets engagement in the latest and earliest beginning

\begin{tabular}{|c|c|c|c|c|c|}
\hline \multirow{2}{*}{$\begin{array}{l}\dot{\grave{x}} \\
\dot{0}\end{array}$} & \multirow[b]{2}{*}{ Day } & \multicolumn{2}{|c|}{ The latest beginning } & \multicolumn{2}{|c|}{ The latest beginning } \\
\hline & & $\begin{array}{c}\text { Current assets } \\
\left(\mathrm{O}_{\mathrm{s}}\right)\end{array}$ & $\begin{array}{c}\text { Cumulative } \\
\mathrm{O}_{\mathrm{s}}\end{array}$ & $\begin{array}{c}\text { Current assets } \\
\left(\mathrm{O}_{\mathrm{s}}\right)\end{array}$ & $\begin{array}{c}\text { Cumulative } \\
\mathrm{O}_{\mathrm{s}}\end{array}$ \\
\hline 1 & 2 & 3 & 4 & 5 & 6 \\
\hline 1. & 0 & 17093264.4 & 17093264.4 & 17621278.8 & 17621278.8 \\
\hline 2. & 15 & 160322.2 & 17253586.5 & 1102684.4 & 18723963.2 \\
\hline 3. & 31 & 171010.3 & 17424596.8 & 607533.2 & 19331496.4 \\
\hline 4. & 38 & 160176.8 & 17584773.6 & 234913.1 & 19566409.5 \\
\hline 5. & 49 & 251706.3 & 17836479.9 & 262787.5 & 19829196.9 \\
\hline 6. & 51 & 439421.3 & 18275901.2 & 417779.5 & 20246976.5 \\
\hline 7. & 60 & 757835.2 & 19033736.4 & 359253.7 & 20606230.1 \\
\hline 8. & 71 & 1787147.2 & 20820883.6 & 1254816.5 & 21861046.6 \\
\hline 9. & 82 & 538927.4 & 2135981.0 & 186600.4 & 22047647.1 \\
\hline 10. & 92 & 574364.0 & 21934175.0 & 169636.8 & 22217283.8 \\
\hline 11. & 101 & 1263621.9 & 23197796.9 & 980513.1 & 2319796.9 \\
\hline 12. & 111 & 117568.4 & 23315365.3 & 117568.4 & 23315365.3 \\
\hline 13. & 122 & 129325.2 & 23444690.5 & 129325.2 & 23444690.5 \\
\hline
\end{tabular}

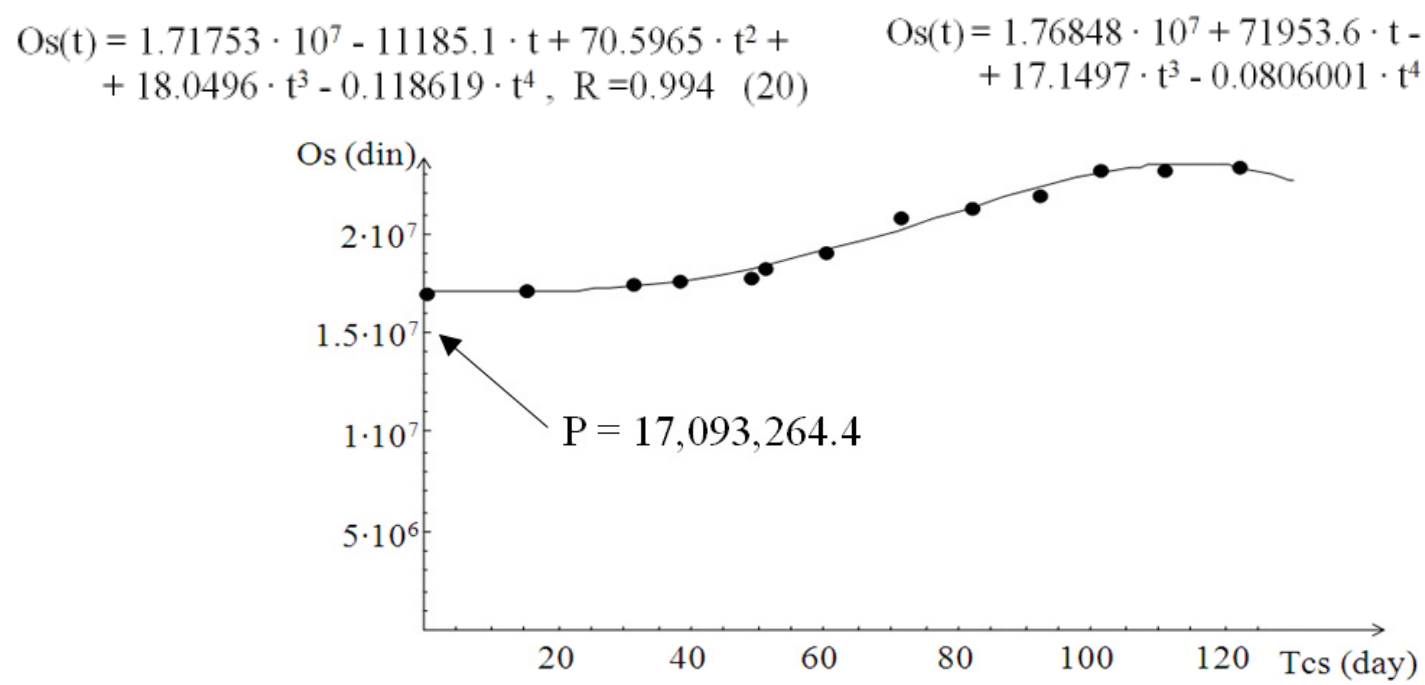

Figure 5: Diagram of current assets engagement (Os) as a function of time (Tcs), the latest beginning

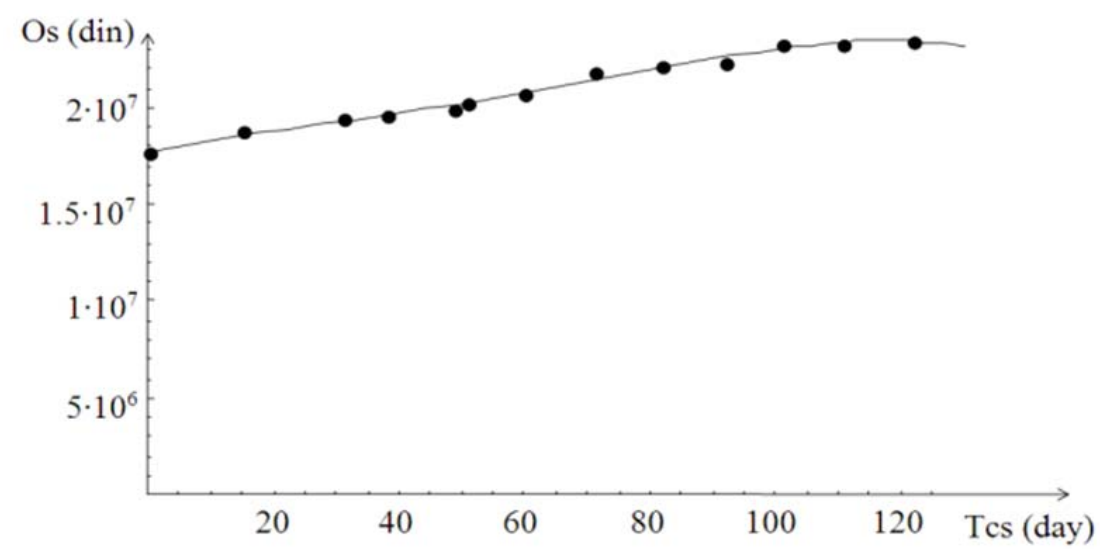

Figure 6: Diagram of current assets engagement (Os) as a function of time (Tcs), 


\section{CONCLUSIONS}

Respecting technical, technological, production and plan documentation and graph theory the paper describes the hierarchical structure of a complex product (Fig. 1). The oriented graph represents a basis for applying the algorithm that synthesizes the processes of optimization, planning, designing and analysis of PC of a complex product and components it is made up of. The systems for weaponry and military equipment production have a specific position and role in the economic environment of the Republic of Serbia. Threats to survival, uncertain trends of changes in the environment, a host of constraints, globalization of business operations and impact of diverse markets impose to 'Sloboda' - Cacak Co. two key dimensions of the strategy: forecasting and risking. Viewed within this context, the principle of economies of times in the manufacturing domain requires thorough investigation and mastering of time and economic dimensions of PCs. The coefficient of time of a complex product is at the satisfactory level (1.27) having in mind the designed and actual PC length (96 and 122 days). Taking into account the scale of uncompleted production, this coefficient value was expected to be lower. The diagrams of assets engagement for two diametrically opposed manners of production organization (Figs 3 and 4) are similar, which indicates a great value of inventories in unfinished production process (point $\mathrm{P}$, Figure 5 ) amounting to $73 \%$.

\section{REFERENCES}

1) Curović, D., Vasić, B., Popović, V., Curović, N.: Ekspertsko planiranje proizvodnje, (2008) Journal of Applied Engineering Science (Istraživanja i projektovanja u privredi), no. 20 , p.49-57

2) Djukic R., Milanovic D., Klarin M., Jovanovic J., Determinants of the dynamic managing of the BPS, Tehnika i praksa, No 1, VSTSS Cacak, Cacak, 2010.

3) Eckert C., Clarkson P., Planning development processes for complex products, $\mathrm{Re}$ search in Engineering Design, Vol. 21(3), p153-171, 2010.

4) Jovanovic J., Milanovic D. D., Djukic R. et al., Analysis of the production cycle and the dynamics of the use of working capital, Tehnika i praksa, No 6, VSTSS Cacak, Cacak, 2011.

5) Uskoković, P.: Planiranje - jedna od osnovnih aktivnosti menadžmenta, (2009) Journal of Applied Engineering Science (Istraživanja i projektovanja za privredu), no. 8, p. 33-41

Paper sent to revision: 30.08.2012.

Paper ready for publication: 26.09.2012. 